\title{
Optimization of Capillary Electrophoresis Separation Conditions of Chlorpromazine, Promethazine and Their Main Metabolites by RSM
}

\author{
Chungeng Li $i^{1}$, Yanling Cheng ${ }^{1,2, *}$, Kaowen Zhou ${ }^{1,2, *}$ \\ ${ }^{1}$ Biochemical Engineering College, Beijing Union University, Beijing 100023, China \\ ${ }^{2}$ Beijing Key Laboratory of Biomass Waste Resource Utilization, Beijing 100023, China \\ *E-mail: zhoukaowen@buu.edu.cn, cheng1012cn@aliyun.com
}

Received: 3 August 2021/ Accepted: 13 September 2021 / Published: 10 October 2021

\begin{abstract}
It is difficult to separate multiple phenothiazines with similar structures by capillary electrophoresis. However, under the experimental conditions optimized by response surface methodology (RSM), ten similar molecules of chlorpromazine, promethazine and their metabolites can be well separated in our experiment. Among them, the resolution of two difficult-to-separate molecules (chlorpromazine sulfoxide and hydroxychlorpromazine) is 1.39 (incomplete separation) under single factor experimental conditions and 1.51 (complete separation) under optimized experimental conditions. The optimum values of $\mathrm{pH}$ of phosphate buffer solution (PBS), concentration of $\mathrm{NaCl}$ in $\mathrm{PBS}$, concentration of tween 40 in PBS and separation voltage were $6.75,49.06 \mathrm{mmol} / \mathrm{L}, 26.58 \mathrm{mmol} / \mathrm{L}$ and $16.86 \mathrm{kV}$, respectively. All of the ten phenothiazines have good linear relationship. The recoveries of standard addition for dog urine samples without pretreatment were $87.3 \%-112.6 \%$.
\end{abstract}

Keywords: Capillary electrophoresis, Chlorpromazine, Promethazine, Metabolite, Response surface methodology

\section{FULL TEXT}

(C) 2021 The Authors. Published by ESG (www.electrochemsci.org). This article is an open access article distributed under the terms and conditions of the Creative Commons Attribution license (http://creativecommons.org/licenses/by/4.0/). 